\title{
EI PRINCIPIO DE JURISDICCIÓN UNIVERSAL EN ESPAÑA Y EN ALGUNOS PAÍSES DE NUESTRO ENTORNO: UN ANÁLISIS DE LA LEGISLACIÓN Y LA PRÁCTICA JUDICIAL
}

\section{Dorina Claudia Suciu ${ }^{1}$}

Universidad de Almería

Email: cs408@inlumine.ual.es

RESUMEN: El objetivo del presente artículo es resaltar el régimen jurídico cada vez más restrictivo del principio de jurisdicción universal, las motivaciones subyacentes en su limitación de forma general a nivel internacional, y la trascendencia de esta nueva configuración en la efectiva persecución y castigo de los crímenes que atentan contra los bienes jurídicos cuya titularidad pertenece a toda la comunidad internacional en su conjunto. Para ello, se realiza un análisis de la legislación vigente en la materia, en España y en otros países de nuestro entorno, y de los procesos judiciales más significativos llevados a cabo en aplicación de este principio.

PALABRAS CLAVE: jurisdicción universal, protección de derechos humanos, discrecionalidad del ministerio fiscal.

ABSTRACT: The purpose of this article is to expose the increasing restrictiveness of the legal regime from the principle of universal jurisdiction, the underlying motivations that have caused this limitation in the international level, and the importance of this new configuration when persecuting and punishing the crimes against legal assets that belong to the international community. For this, an analysis of the legislation that covers this area is made, focusing in Spain and other similar countries, and of the more important judicial processes carried out under this principle.

KEYWORDS: universal jurisdiction, human rights protection, general attorney discretion.

\footnotetext{
${ }^{1}$ Graduada en Derecho y Máster en Abogacía por la Universidad de Almería. Doctoranda en el Área de Derecho Internacional Público y Relaciones Internacionales de la Universidad de Almería.
} 


\section{I.- LOCALIZACIÓN DEL PRINCIPIO DE JURISDICCIÓN UNIVERSAL. CONCEPTO Y FUNDAMENTOS.}

La soberanía de un Estado, entre otros elementos, se manifiesta directamente en la configuración del ius puniendi del Estado en cuestión, y su relevancia en el tema que nos ocupa es el impacto que causa sobre la delimitación de la aplicabilidad de la ley penal en el espacio. Ante la comisión de un ilícito penal, la regla general de atribución de la competencia para la investigación y el enjuiciamiento de los hechos es el principio de territorialidad, considerado como criterio principal de determinación de la jurisdicción tanto en el Derecho nacional como internacional. Como se sabe, la ley penal de un Estado se aplica a los hechos cometidos en su territorio, sean nacionales o extranjeros los sujetos intervinientes en el delito, o en sentido contrario, la ley penal de un Estado no se aplica a los hechos cometidos fuera de su territorio. A estos efectos, conviene indicar que el concepto jurídico de territorio no coincide completamente con el concepto geográfico del mismo ${ }^{2}$, comprendiendo todos aquellos lugares sobre los que un Estado extiende su soberanía ${ }^{3}$.

Este principio de territorialidad no es inamovible, sino que a través del consenso internacional se han llegado a configurar una serie de excepciones. Ya en 1927 la Corte Permanente de Justicia Internacional manifestaba, en el asunto Lotus, que la "territorialidad del Derecho Penal no es un principio absoluto del Derecho Internacional"4. Es por ello que debemos hablar de supuestos de extraterritorialidad de

\footnotetext{
${ }^{2}$ Vid. Polaino naVarrete, M., Derecho Penal Parte General Tomo I: Fundamentos Científicos del Derecho Penal, 4ª Edición, Bosch, Barcelona, 2001, p. 453, citado en ANDRÉS DOMÍNGUEZ, A., Derecho Penal Internacional, $1^{\text {a }}$ Edición, Tirant Lo Blanch, Valencia, 2006, p. 158.

${ }^{3}$ Vid. GARCÍA SÁNCHEZ, B., Límites a la ley penal en el espacio, Atelier, Barcelona, 2004, p. 29, citado en ANDRÉS DOMÍNGUEZ, A., Derecho Penal Internacional..., Op. cit., pp. 158-159.

${ }^{4}$ En este asunto, Turquía se enfrentaba a Francia por unos Delitos cometidos en el Alta Mar. Vid. S.S. Lotus (1927) Corte Permanente de Justicia Internacional, Ser. A, No. 10. "Aunque es cierto que en todos los sistemas legales es fundamental el carácter territorial del Derecho penal, no es menos cierto que todos o casi todos esos sistemas extienden su jurisdicción a delitos cometidos más allá del territorio del Estado. Consecuentemente, la territorialidad del Derecho penal no es un principio absoluto del Derecho Internacional y de ninguna manera coincide con la soberanía territorial." Disponible en: http://www.dipublico.org/10984/s-s-lotus-1927-corte-permanente-de-justicia-internacional-ser-a-no-10/; Conviene, no obstante añadir la sentencia de la Corte Internacional de Justicia, en el asunto República Democrática del Congo c. Bélgica, de 12 de febrero de 2002. En este supuesto, Bélgica defendía que las inmunidades conferidas a los Ministros de Relaciones Exteriores no pueden en ningún caso protegerlos cuando ellos son sospechosos de haber cometido crímenes de guerra o crímenes contra la humanidad. Sin
} 
la ley penal de un Estado, encontrándose su fundamento en otros títulos de atribución de la jurisdicción. Los títulos tradicionalmente reconocidos son el principio de personalidad o de nacionalidad, en el que el elemento que determina qué Estado es el competente para aplicar su ley penal (distinto del lugar en el que se han cometido los hechos), es la nacionalidad de un sujeto $^{5}$; y el denominado principio real o de protección de intereses, fundamentado en la necesidad de los Estados de proteger más allá del límite de sus fronteras ciertos intereses nacionales que, en el lugar en el que se ha cometido el delito, no se protegen o el grado de protección no es considerado suficiente por el Estado lesionado ${ }^{6}$. Para finalizar este esquema de foros jurisdiccionales, hay que añadir, como complemento de los anteriores, un título que actúa de forma excepcional, el principio de justicia universal, que ha te entenderse en términos absolutos, tal como ha sido definido en los Principios de Princeton: aquél que permite el ejercicio de la jurisdicción de un Estado más allá de sus fronteras, sin que exista conexión alguna de territorio, nacionalidad, o intereses nacionales ${ }^{7}$. Los Estados, no obstante, coinciden en la idea de subsidiariedad en la aplicación de la ley penal extraterritorialmente, por lo que sólo actuarían conforme a estos principios excepcionales si el Estado territorial no lleva a cabo actuación alguna.

embargo, la Corte, pronunciándose a favor de los argumentos de la República Democrática del Congo, no deducía la existencia, en derecho internacional consuetudinario, de excepciones a la regla de la inmunidad de jurisdicción en materia criminal e inviolabilidad de la que goza un Ministro de Asuntos Exteriores, por ser sospechoso de haber cometido un crimen de guerra o un crimen contra la humanidad. Caso de la Orden de Detención de 11 de abril de 2000 (La República Democrática del Congo contra Bélgica) Fallo de 14 de febrero de 2002. Un resumen de este fallo está disponible en: http://www.icjcij.org/homepage/sp/files/sum 1997-2002.pdf.

5 Vid. LUZÓN PEÑA, D., Lecciones de Derecho Penal. Parte general, $3^{\mathrm{a}}$ Edición, Tirant Lo Blanch, Valencia, 2016, pp. 113.

${ }^{6}$ Vid. ANDRÉS DOMÍNGUEZ, A., Derecho Penal Internacional..., Op. cit., pp. 172-173.

${ }^{7}$ El Proyecto de Princeton tuvo origen en una visita efectuada a Princeton en enero de 2000 por William J. Butler y Stephen A. Oxman, quienes, en representación de la Comisión Internacional de Juristas y la Asociación Norteamericana pro Comisión Internacional de Juristas, propusieron la idea de formular principios que contribuyeran a elucidar y ordenar una esfera del derecho penal internacional que adquiere cada vez más importancia: la del enjuiciamiento en tribunales nacionales de delitos graves de derecho internacional, con arreglo a la jurisdicción universal y cuando no existan nexos jurisdiccionales tradicionales con las víctimas o los perpetradores de los crímenes. Así, los Principios de Princeton sobre la Jurisdicción Universal de 2001, son el resultado de un examen de la legislación internacional sobre jurisdicción universal, realizado por diversos académicos y expertos durante un período de un año. La Asamblea General de las Naciones Unidas publica la versión en español en el DOC. A/56/677. Disponible

en: http://www.un.org/es/comun/docs/index.asp?symbol=A\%2F56\%2F677\&Submit=Buscar\&Lang=S. En el Principio 1, se define la jurisdicción universal absoluta como: "una jurisdicción penal sustentada exclusivamente en la naturaleza del delito, prescindiendo del lugar en que este se haya cometido, la nacionalidad del autor presunto o condenado, la nacionalidad de la víctima o cualquier otro nexo con el Estado que ejerza esa jurisdicción". 
Centrándonos en el último principio mencionado, históricamente, se considera que la primera caracterización doctrinal de la justicia universal fue la realizada por el jurista holandés Hugo Grocio a principios del siglo XVII:

“...debe saberse que los reyes, y aquellos que tienen poder igual al de los reyes tienen el derecho de infligir penas no sólo por las injusticias cometidas contra ellos y sus súbditos, sino aun por aquellos que no los afectan particularmente y que violan hasta el exceso el derecho de la naturaleza o de gentes respecto de cualquiera que sea el autor de los excesos"

Con esta caracterización podemos entrever el alcance de la justicia universal como instrumento de protección de aquellos bienes jurídicos cuya titularidad pertenece a la Comunidad internacional en su conjunto, que amenazan la paz y la seguridad, teniendo especial transcendencia sobre los derechos humanos 9 . La naturaleza internacional de estos crímenes es el primer fundamento del principio de justicia universal y, abandonado toda idea de territorialidad, para sostener esta teoría Werle apunta que:

"Los efectos de actos dirigidos en contra de los intereses más elevados de la comunidad internacional no quedan limitados al territorio interno del Estado en el que se cometen: los crímenes de derecho internacional no son asuntos internos y no rigen respecto de ellos los límites que el derecho internacional sienta a la expansión del poder punitivo del Estado, sobre todo en el marco del principio de no injerencia" ${ }^{\prime 10}$.

Cuando hablamos de crímenes de Derecho internacional, nos referimos a situaciones globalmente rechazadas, cuyo contenido atroz trasciende las fronteras físicas de los

\footnotetext{
${ }^{8}$ Vid. RABINOVITCH, R., "Universal Jurisdiction in Abstentia", Fordham International Law Journal, Volume 28, Issue 2, Article 8, 2004, p. 516; OLLÉ SESÉ, M., Justicia universal para crímenes internacionales, La Ley, Madrid 2008, p. 97; REYDAMS. L., "The Rise and Fall of Universal Jurisdiction", Working Paper of Katholieke Universiteit Leuven No. 37 - January 2010, pp. 10 - 12.

${ }^{9}$ Vid. CHINCHÓN ÁlVAREZ, J., "El Principio de jurisdicción universal. Concepto y Fundamentos lógico y jurídico", Tiempo de Paz, no 112, 2014, pp. 6-12.

${ }^{10}$ WERLE, G., Tratado de Derecho Penal Internacional, $2^{\mathrm{a}}$ edición, Tirant Lo Blanch, Valencia, 2011, p.137.
} 
Estados, requiriendo por ello una respuesta fundada en las normas internacionales ${ }^{11}$. El origen de esta necesidad se encuentra en las numerosas ocasiones en las que se ha evidenciado, que en la persecución de estos crímenes, el poder individual de un Estado no es suficiente, bien porque ese poder sea incapaz para llevar a cabo una investigación eficaz y concluir esa investigación con un proceso judicial con todas las garantías requeridas en el Derecho internacional, bien porque desde ese poder individual se decida no llevar a cabo actuación de persecución alguna con el objetivo de sustraer a los perpetradores de la acción de la justicia, facilitando su impunidad ${ }^{12}$.

En definitiva, se trata de hechos delictivos que devienen inadmisibles en el entorno internacional actual, en el que la globalización y la modernización han favorecido la proliferación a nivel mundial de crímenes masivos cuyos resultados son de tal envergadura que no pueden quedar impunes. Una explicación reveladora de las implicaciones de esta afirmación sería la que nos ofrece BERDUGO GÓMEZ DE LA TORRE, que nos dice que "la existencia de una respuesta frente al delito de genocidio interesa a toda la humanidad, mientras que la respuesta frente a un asesinato interesa al país en el que se produce" ${ }^{\prime 13}$. Ante la pasividad del Estado en el que se han cometido los hechos, en ocasiones motivada por la hipotética trascendencia socioeconómica y política que tendría un enjuiciamiento, se hace necesaria la intervención de un tercero que procure y ponga los medios necesarios para que esa impunidad no se produzca.

En tanto en cuanto un Estado ejerce su jurisdicción sobre un crimen de Derecho Internacional, fundamentando su competencia en el principio de justicia universal, se está convirtiendo en el representante de toda la Comunidad internacional en ese asunto, actuando en defensa de intereses colectivos o universales ${ }^{14}$. En resumen, estamos

\footnotetext{
${ }^{11}$ Vid. MCKAY, F., Universal Jurisdiction in Europe. Criminal prosecutions in Europe since 1990 for war crimes, crimes against humanity, torture and genocide, REDRESS, 1999, p. 3.

${ }^{12}$ Vid. GARCÍA ARÁN, M., "El principio de justicia Universal de la L.O. del Poder Judicial español", AA.VV., Crimen internacional y jurisdicción universal. (El Caso Pinochet), Tirant Lo Blanch, Valencia, 2000 , p. 71.

${ }^{13}$ Vid. BERDUGO GÓMEZ DE LA TORRE, I., "Acerca de la Internacionalización del Derecho Penal", AA.VV., El principio de Justicia universal: Fundamentos y límites, Tirant Lo Blanch, Valencia, 2012, p. 23.

${ }^{14}$ Tradicionalmente es aceptado en el entorno internacional que los bienes jurídicos protegidos por los denominados crímenes de derecho internacional, forman parte de las normas de ius cogens, como consecuencia directa de su importancia y de la consideración de toda la humanidad como titulares de los mismos. Progresivamente se ha ido reconociendo un conjunto de intereses como pertenecientes al orden
} 
reflexionando sobre el "principio de solidaridad universal en materia de enjuiciamiento penal" 15 , siendo la función primordial del título universal, servir a la humanidad en su conjunto como instrumento a disposición de los Estados para que estos puedan cumplir con la obligación de perseguir, investigar y castigar determinados crímenes, para los que investidos de competencia por la ley y el consenso internacional.

Esta "solidaridad universal" también se puede observar en otro ámbito más allá de las relaciones de unos Estados con otros, manifestándose en la complementariedad de las actuaciones estatales con las de los órganos jurisdiccionales internacionales, desde los que también se fomenta el uso del principio de jurisdicción universal. Es lo que ocurrió en el Tribunal Penal Internacional para Ruanda donde en el marco del enjuiciamiento del caso Ntuyahaga alentó a todos los Estados en aplicación de éste principio "a procesar y juzgar a aquellos responsables de serios crímenes tales como el genocidio, crímenes contra la humanidad y otras graves violaciones del derecho internacional humanitario" ${ }^{16}$. En esta misma línea, en el preámbulo del Estatuto de la Corte Penal

público supranacional, en cuya preservación los Estados están comprometidos a través de los distintos Tratados suscritos. En este sentido, la Convención para la Prevención y la Sanción del Delito de Genocidio, aprobada por la Asamblea General de las Naciones Unidas el 9 de diciembre de 1948, la Convención contra la Tortura y otros Tratos o Penas Crueles, Inhumanos o Degradantes, hecha en Nueva York el 10 de diciembre de 1948, y, los Convenios de Ginebra (I) para aliviar la suerte de los heridos y enfermos de las fuerzas armadas en campaña, (II) para mejorar la suerte de los heridos, enfermos y náufragos de las fuerzas armadas en el mar, (III) relativo al trato debido a los prisioneros de guerra, (IV) relativo a la protección de las personas civiles en tiempo de guerra, aprobados el 12 de agosto de 1949 por la Conferencia Diplomática para elaborar Convenios Internacionales destinados a proteger a las víctimas de la guerra. Igualmente la Convención sobre la Imprescriptibilidad de los Crímenes de Guerra y de los Crímenes de Lesa Humanidad, hecha en Nueva York el 26 de noviembre de 1968, la Convención Internacional sobre la Represión y el Castigo del Crimen de Apartheid, hecha en Nueva York el 30 de Noviembre de 1972, los Protocolos adicionales a los Convenios de Ginebra relativos a (I) la Protección de las víctimas de los Conflictos Armados Internacionales y (II) la Protección de las víctimas de los Conflictos Armados sin Carácter Internacional, adoptados el 8 de junio de 1977, y el Estatuto de Roma de la Corte Penal Internacional, hecho en Roma el 17 de julio de 1998. Vid. PÉREZ CEPEDA, A., "Principio de Justicia penal universal versus principio de Jurisdicción penal internacional”, AA.VV., El principio de Justicia universal: Fundamentos y límites, Op. cit., pp. 66-77.

${ }^{15}$ LAMARCA PÉREZ, C., "El principio de justicia universal y la competencia de la jurisdicción española en los casos de Argentina y chile", Revista de Derecho Penal y Criminología, $2^{\mathrm{a}}$ Época, $\mathrm{n}^{\mathrm{o}}$ extraordinario $1^{\circ}, 2000$, p. 61.

${ }^{16}$ Prosecutor v. Ntuyahaga, Case No. ICTR-98-40-T, Decision on the Prosecutor's Motion to Withdraw the Indictment (Mar. 18, 1999) 1. On the withdrawal of the indictment: "Whereas, that said, the Tribunal wishes to emphasize, in line with the General Assembly and the Security Council of the United Nations, that it encourages all States, in application of the principle of universal jurisdiction, to prosecute and judge those responsible for serious crimes such as genocide, crimes against humanity and other grave violations of international humanitarian law." Disponible en: http://unictr.unmict.org/sites/unictr.org/files/case-documents/ictr-98-40/trial-decisions/en/990318.pdf. 
Internacional se afirma que "los crímenes más graves de gran trascendencia para la Comunidad internacional en su conjunto no deben quedar sin castigo"17.

Todo ello, sin duda alguna, nos conduce a la representación teórica de lucha contra la impunidad en la perpetración de graves crímenes y en la consideración de la justicia universal como instrumento eficaz para la consecución de este objetivo ${ }^{18}$. No sólo como herramienta activa en la reparación del daño, que normalmente no es posible más allá de una reparación moral, de saber que el responsable ha sido castigado, sino también como mecanismo preventivo o coercitivo, que incida de manera represiva sobre las intenciones delictivas con tal magnitud que provoque un replanteamiento de las mismas, y es que, "la persuasión de no encontrar un palmo de tierra que perdonase a los verdaderos delitos sería un medio efícacísimo de evitarlos” ${ }^{\prime 19}$. Nos referimos a una representación teórica, y ello porque en la práctica su regulación y aplicación, sobre todo si se pretende que sea en términos absolutos, resulta muy controvertida ${ }^{20}$. Este es el aspecto que trataremos de forma más detallada en el siguiente apartado, donde intentaremos sacar a relucir la existencia de jurisdicciones universales restringidas o relativas, alejadas de la concepción inicial de este principio, que lo desvían de su objetivo último, sin argumentos bastantes que permitan entender o al menos justificar suficientemente esas limitaciones.

\footnotetext{
${ }^{17}$ Preámbulo Estatuto de Roma de la Corte Penal Internacional, hecho en Roma el 17 de julio de 1998, BOE núm., 126, de 27 de mayo de 2002; Vid. RODRÍGUEZ YAGÜE, C., "El principio de justicia universal y los conflictos positivos de concurrencia de jurisdicciones nacionales y supranacionales", AA.VV., El derecho penal frente a la inseguridad global, Bomarzo, Albacete, 2007, p. 29.

18 Vid. CHINCHÓN ÁlVAREZ, J., "Análisis formal y material de la reforma del principio de jurisdicción universal en la legislación española: De la "abrogación de facto" a la "derogación de iure"”, Diario la Ley, $\mathrm{n}^{\circ}$ 7211, Sección Doctrina, 6 Jul. 2009, La Ley.

${ }^{19}$ BECCARIA, C., Tratado de los delitos y de las penas, Universidad Carlos III de Madrid, 2015. Citado en LAMARCA PÉREZ, C., Op. cit., p. 60.

${ }^{20}$ El día 29 de junio de 2009 se dirigía a la Asamblea General de las Naciones Unidas una petición de inclusión de un tema adicional en la agenda de la sexagésima tercera sesión, en concreto, "El alcance y la aplicación del principio de la jurisdicción universal". La petición, venía formulada por el Representante Permanente de la República Unida de Tanzania ante las Naciones Unidas y se fundamentaba en la preocupación que afloraba en la Unión Africana, sobre una posible aplicación arbitraria del principio, en particular hacia los líderes africanos. Ante esta solicitud se aprueba la inclusión del tema y se solicita a los Estados que emitan sus consideraciones para la sexagésima cuarta sesión. Disponible en: https://documents-dds-ny.un.org/doc/UNDOC/GEN/N09/421/28/PDF/N0942128.pdf?OpenElement.
} 


\section{II.- LA JURISDICCIÓN UNIVERSAL EN ESPAÑA Y EN EL DERECHO COMPARADO}

\section{Jurisdicción universal relativa}

Al realizar un breve estudio de derecho comparado, localizamos Estados que no reconocen la existencia de la jurisdicción universal como tal, sino que requieren la presencia de determinados vínculos que justifiquen la intervención de sus órganos judiciales. Estos nexos pueden ser de nacionalidad, la presencia del acusado en su territorio para iniciar la investigación, o que el Estado en cuestión venga obligado a perseguir y castigar esos crímenes por un acuerdo internacional. Así, desde el primer momento han regulado una jurisdicción universal relativa los siguientes Estados: a saber, Austria, Estados Unidos, Francia, Países Bajos, Noruega, Reino Unido de Gran Bretaña e Irlanda del Norte, Alemania, Australia y la República Popular China, entre otros.

Comenzaremos con Austria, donde la regulación referente al principio que nos ocupa se infiere de una serie de preceptos en los que se reconoce la posibilidad de la aplicación extraterritorial de su ley penal ${ }^{21}$. Así, se diferencian dos grupos de hechos delictivos cometidos en el extranjero, sobre los cuales las autoridades austriacas tienen competencia, exigiendo para su activación requisitos diferentes según estemos en uno u otro caso. Para el primer grupo de ilícitos, la ley penal austriaca es aplicable independientemente de la ley aplicable en el lugar de comisión de los hechos, si como consecuencia de estos crímenes se ven afectados intereses nacionales o si su persecución y castigo es una obligación derivada de un Tratado internacional. Para los crímenes contenidos en el segundo grupo, sólo es aplicable si estos son perseguibles en el lugar de comisión de los hechos, siendo requisito imprescindible para el inicio de las actuaciones judiciales que el delincuente extranjero se encuentre en territorio austriaco y

\footnotetext{
${ }^{21}$ Vid. "Permanent Mission of Austria to the United Nations, No. 66.000/2/2010". Respuesta a la Resolución de la Asamblea General 64/117, DOC. A/RES/64/117. Disponible en: http://www.un.org/en/ga/sixth/65/ScopeAppUniJuri_StatesComments/Austria.pdf.
} 
no pueda ser extraditado por razones distintas a la naturaleza o las características del crimen $^{22}$.

El Derecho austriaco es un ejemplo de un sistema basado en el principio de la legalidad. Su Código Procesal Penal (Strafprozeßordnung, StPO), impone al Fiscal la obligación de sostener la acusación en un juicio en todos aquellos hechos delictivos que lleguen a su conocimiento, a excepción de los delitos perseguibles únicamente a instancia de parte, y a excepción de aquellos delitos cometidos en el extranjero cuando la obligación de desistir de la acusación venga determinada por un Tratado internacional ${ }^{23}$. Siendo los supuestos en los que puede no acusar tasados y determinados de manera objetiva, no plantea mayores problemas en lo que respecta a la discrecionalidad de la Fiscalía, que como más adelante veremos, en otros Estados se convierte en una verdadera dificultad. En cuanto a la práctica judicial, siendo esta muy escasa, actualmente, se puede mencionar como intento de enjuiciamiento, el caso contra el serbobosnio Dusko Cvjetokovic, de 1994, por presunto genocidio, asesinato e incendio, cometidos en Bosnia y Herzegovina. Procesalmente se admitió la jurisdicción austriaca, sin embargo, el proceso fracasó en cuanto al fondo del asunto, al no ser posible la identificación del autor por parte de los testigos de la acusación ${ }^{24}$.

Siguiendo con el análisis, nos detenemos ahora en Estados Unidos. Tradicionalmente territorial, es un Estado que al igual que el anterior, no ha incorporado a su legislación el principio universal, sino que configura ciertos supuestos de extraterritorialidad ${ }^{25}$. La ley penal estadounidense se compone de un Código Penal Federal (Código de los Estados Unidos, (U.S.C)) aplicable a todos los Estados federados y un Código Penal específico

\footnotetext{
22 Ambos grupos de ilícitos se localizan en el Criminal Code Section 64 - Criminal offences abroad punishable irrespective of the laws which are valid at the place of comission, el primero de ellos y en el Criminal Code Section 65 - Criminal offences committed abroad which are subject to prosecution only if they are liable to prosecution according to te laws which are valid at the scene of the crime, el segundo.

${ }^{23}$ Vid. "Prosecution: Comparative Aspects - The Decision to Prosecute - Prosecutor, Court, Victim, Charges, Criminal and Prosecutor". Disponible en: http://law.jrank.org/pages/1855/ProsecutionComparative-Aspects-decision-prosecute.html\#ixzz4JPCb1Rv5. Última consulta en agosto de 2016. Citado en REDRESS, Extraterritorial jurisdiction in the European Union: A study of the laws and practice in the 27 member States of the European Union, 2010, p. 72.

${ }^{24}$ Ibídem, pp. 75-77.

25 Vid. "United States Submission Information and Observation on the Scope and Application of the Principle of Universal Jurisdiction". Respuesta a la Resolución 64/117. Disponible en: http://www.un.org/en/ga/sixth/65/ScopeAppUniJuri_StatesComments/United\%20States.pdf.
} 
para cada uno de estos Estados ${ }^{26}$. Centrándonos en el Código común hay una serie de preceptos que confieren jurisdicción a los órganos estadounidenses, en los que el único nexo con Estados Unidos es la presencia del presunto culpable en el territorio del país. La inclusión de estas excepciones, que en su gran mayoría se refieren a terrorismo internacional, se debe a que Estados Unidos es parte en determinados Tratados que imponen esta obligación, sin embargo, también hay excepciones derivadas de la naturaleza universal de los crímenes a los que se refieren ${ }^{27}$.

En este país es esencial la intervención de la Fiscalía, pues no se puede iniciar un procedimiento penal si no es mediante la acusación del Fiscal federal, sin que exista la posibilidad de que los particulares presenten denuncias ante los tribunales. Entre los procesos fundamentados en las excepciones anteriormente apuntadas se encuentran: el de Ramzi Yousef, en el año 1998, enjuiciado y condenado por varios delitos relacionados con la participación que tuvo en el atentado con bombas de 1993 contra el World Trade Center en Nueva York y por conspiración para atentar con bombas contra varios aviones comerciales de EE.UU en Asia en 1994 y 1995; y el del hijo del expresidente de Liberia Charles Taylor, Charles "Chuckie" Taylor Jr. juzgado y sentenciado en 2008 por tortura y otros delitos conexos cometidos durante el régimen de su padre en Liberia entre el año 1999 y 2003.

Las limitaciones también son evidentes en la legislación francesa. El principio de jurisdicción universal se regula en el artículo 689.1 a 689.11 del "Code de Procédure Pénale" y se trata de una lista de hechos punibles que deben ser enjuiciados por los tribunales franceses como consecuencia de la firma y ratificación de determinados Tratados internacionales ${ }^{28}$. El requisito exigido es la presencia del presunto responsable

26 El Código Común para todos los Estados Federados se encuentra disponible en: http://uscode.house.gov/. Última consulta en agosto de 2016.

27 Es lo que sucede por ejemplo en el caso de la piratería, el genocidio y los crímenes de tortura, localizados en el U.S.C. en los siguientes preceptos: Piratería, U.S.C., título 18, Sección 1651, Genocidio, U.S.C., título 18, Sección 1091, y Tortura, U.S.C., título 18, Sección 2340a . En estos supuestos la jurisdicción de los tribunales estadounidenses se activa cuando el responsable se encuentre en territorio estadounidense.

${ }^{28}$ Vid. SÁNCHEZ LEGIDO, A., "El fin del modelo español de la jurisdicción universal”, Revista Electrónica de Estudios Internacionales, $\mathrm{n}^{\circ}$ 27, 2014, p. 17. En el artículo 689.11 el Código Procesal Penal se establece que cualquier persona que sea residente habitual en el territorio de la República y que sea considerada responsable de un crimen cometido en el extranjero que entre dentro de la competencia de la Corte Penal Internacional, puede ser juzgado por los tribunales franceses. Este precepto fue 
en territorio francés, lo que convierte este tipo de jurisdicción en una "quasiuniversal $^{, 29}$, siendo en todo caso necesario el ejercicio de la acción penal por el Ministerio Público ${ }^{30}$. Igualmente se puede llevar a cabo un proceso fundamentado en el principio de jurisdicción universal, de conformidad con las leyes especiales de cooperación con los Tribunales Penales Internacionales para la antigua Yugoslavia y Ruanda, respecto de aquellos crímenes tipificados en sus Estatutos ${ }^{31}$. Se establece un sistema de subsidiariedad, en relación con otras jurisdicciones preferentes, basadas en vínculos de territorio y nacionalidad, al no ser competentes los órganos franceses cuando un Tribunal Penal Internacional o el Estado de la nacionalidad del autor, estén conociendo del asunto ${ }^{32}$.

Los tribunales franceses han llevado a término numerosos procesos y entre ellos podemos aludir, en primer lugar, al caso seguido contra Dupaquier et al $v$. Munyeshyaka, en el año 1996, por la comisión de crímenes internacionales tipificados en el Estatuto del Tribunal Penal Internacional para Ruanda. La presencia en el territorio francés del presunto culpable fue un requisito importante y aunque en principio se pretendía que se desarrollara el juicio por los crímenes de tortura, genocidio o crímenes de lesa humanidad, los tribunales se declararon competentes para conocer únicamente del delito de tortura ${ }^{33}$. En segundo lugar, al Caso Ould Dah, de 2005, en el que el acusado era un General de Estado de Mauritania, los tribunales franceses debían decidir si se consideraban competentes teniendo en cuenta la amnistía declarada por Mauritania. Lo llamativo de esta causa es que el General fue detenido y procesado en territorio francés y posteriormente puesto en libertad y aunque huyó de Francia, la causa no se

modificado en este sentido por la ley de adaptación de la legislación francesa al Estatuto de la Corte Penal Internacional "LOI $n^{\circ} 2010-930$ du 9 août 2010 portant adaptation du droit pénal à l'institution de la Cour pénale internationale”.

${ }^{29}$ Vid. "The scope and application of the principle of universal jurisdiction", Permanent Mission of France to the United Nations. Respuesta a la Resolución 64/117. Disponible en: http://www.un.org/en/ga/sixth/65/ScopeAppUniJuri_StatesComments/France_E.pdf.

30 Vid. REDRESS, Op. cit., pp. 132-133. La decisión del Ministerio Público puede ser revisada limitadamente por el Fiscal General o por el Ministerio de Justicia.

${ }^{31}$ Con la incorporación de los Estatutos de estos dos Tribunales Internacionales, Francia, pretendía demostrar su cooperación efectiva en la lucha contra la impunidad, lo que permite además de perseguir esos crímenes y de iniciar procesos judiciales cuando los responsables son encontrados en Francia, que ambos Tribunales puedan transferir casos a los órganos jurisdiccionales Franceses.

${ }^{32}$ Artículo 689.11 el Código Procesal Penal. Se hace necesaria la intervención del Ministerio Público, que asegura que la Corte Penal ha renunciado expresamente a su jurisdicción y que ningún otro Tribunal Internacional competente ha solicitado la liberación del detenido en territorio francés y que ningún tribunal nacional de otro Estado ha solicitado su extradición.

${ }^{33}$ Vid. MCKAY, F., Op. cit., p. 26. 
archivó sino que se dictó la resolución en su ausencia. El caso llegó al Tribunal Europeo de Derechos Humanos, donde se consideró que la Ley de Amnistía mauritana no era suficiente en sí misma para imposibilitar la aplicación de la ley francesa por los tribunales franceses. Estos conocieron del caso en aplicación de la justicia universal reconocida por sus propias leyes y el proceso estaba bien fundamentado. Todo ello teniendo en cuenta que la Ley de Amnistía fue aprobada con anterioridad a que los órganos jurisdiccionales mauritanos conocieran de un proceso contra el general, con el fin de sustraerle de la acción de la justicia ${ }^{34}$.

Similar configuración encontramos en los Países Bajos. Los crímenes de derecho internacional pueden ser perseguidos por sus órganos jurisdiccionales, en aplicación del principio universal, cuando el presunto responsable se encuentre en territorio holandés. Son de aplicación el "International Crimes Act", cuya entrada en vigor se produjo en octubre del año 2003, en lo que a genocidio, crímenes de guerra, tortura y crímenes contra la humanidad se refiere, y el "Netherlands Criminal Code", en lo que respecta a la piratería ${ }^{35}$. La Fiscalía tiene atribuido un amplio grado de discrecionalidad bajo el denominado principio de conveniencia, pudiendo decidir acusar o no basándose en las consecuencias que su decisión acarrearía sobre intereses públicos ${ }^{36}$. Bajo este régimen no se ha juzgado todavía a ninguna persona aunque sí ha habido procesos conforme a la regulación anterior, y es de destacar el intento fallido de proceso contra el General Augusto Pinochet, iniciado en 1994, justificado por los tribunales en la existencia de “demasiados obstáculos judiciales" para su desarrollo ${ }^{37}$.

El principio de territorialidad ligado al principio de soberanía estatal inspira igualmente el ordenamiento jurídico del Reino Unido de Gran Bretaña e Irlanda del Norte, basándose "en la tradición según la cual, como norma general las autoridades del Estado

\footnotetext{
34 "Observations on the scope and application of the universal criminal jurisdiction in the work of the Council of Europe". Respuesta a la Resolución de la Asamblea General 67/98. DOC. A/RES/67/98. Disponible en: http://www.un.org/en/ga/sixth/68/UnivJur/CouncilofEu_E.pdf.

35 "The Permanent Mission of the Kingdom of the Netherlands to the United Nations, No. NYV/2010/1628" Información proporcionada en respuesta a la Resolución 64/117. Disponible en: http://www.un.org/en/ga/sixth/65/ScopeAppUniJuri_StatesComments/Netherlands.pdf.

${ }^{36}$ Vid. REDRESS, Op. cit., pp. 194-195. Criminal Procedure Code, Sections 67 and 242 En este mismo estudio se apunta que la decisión de la fiscalía puede impugnarse por las partes interesadas en los tribunales de apelación - Criminal Procedure Code, Sections 12 to 13a).

${ }^{37}$ Vid. MCKAY, F., Op. cit., p. 35.
} 
en cuyo territorio se ha cometido un delito están en mejores condiciones para entablar acciones jurídicas, habida cuenta de la disponibilidad de las pruebas y los testigos y la visibilidad de la justicia en pro de la víctima"38, oponiéndose a los principios de personalidad y jurisdicción universal ${ }^{39}$. Sin embargo hay normas en las que se regula la aplicación del principio cuyo estudio nos ocupa como por ejemplo, la Ley referente a los Convenios de Ginebra, de $1957^{40}$, y la Ley sobre la Corte Penal Internacional de 2001 que introduce en la normativa inglesa los crímenes sobre los que tiene competencia la Corte Penal Internacional ${ }^{41}$. Para proceder al enjuiciamiento de estos crímenes de derecho internacional es necesario el consentimiento del Fiscal General, que no está sujeto a requisito alguno, pudiendo basarse en la existencia de interés público en el asunto ${ }^{42}$. Uno de los procesos desarrollados con arreglo al principio de jurisdicción universal por los órganos de Reino Unido fue el de Fayardi Zardad, de nacionalidad afgana, condenado en 2005 por conspiración para cometer actos de tortura y para tomar rehenes en Afganistán ${ }^{43}$. Asimismo, es importante mencionar también el proceso contra Szymon Serafinovicz, residente en el Reino Unido, acusado en 1997 de haber cometido crímenes de guerra, por matar a tres personas en 1941 -1942, en un campo de concentración bielorruso donde ejercía de guardia ${ }^{44}$.

\footnotetext{
${ }^{38}$ Informe del Secretario General de la Asamblea General de las Naciones Unidas sobre el alcance y aplicación del principio de jurisdicción universal. DOC. A/66/93 p. 18. Disponible en: http://www.un.org/es/comun/docs/?symbol=A/66/93.

39 "Scope and application of the principle of universal jurisdiction. UK Mission to the UN, 15 april 2011 ". Respuesta a la Resolución de la Asamblea General 65/33. DOC. A/RES/65/33. Disponible en: http://www.un.org/en/ga/sixth/66/ScopeAppUniJuri_StatesComments/UK\&Northern\%20Ireland.pdf.

${ }^{40}$ Define en su artículo 1 su ámbito de aplicación estableciendo que se aplica a cualquier persona con independencia de su nacionalidad que cometa o ayude a cometer los hechos prohibidos por los Convenios de Ginebra. Se aplica por tanto a los crímenes recogidos en el artículo 50 del Convenio (I), 51 del Convenio (II), 130 del Convenio (III) 147 del Convenio (IV) y desde el año 2009 también a las violaciones graves contenidas en el Protocolo adicional I de 1997 a los Convenios de Ginebra. Disponible en: http://www.legislation.gov.uk/ukpga/Eliz2/5-6/52. Última consulta en agosto de 2016.

${ }^{41}$ International Criminal Court Act 2001. Establece en su sección 51, que serán punibles los crímenes de guerra, genocidio y lesa humanidad cometidos por un nacional inglés, por un residente en Reino Unido o por una persona que quede sujeta a la jurisdicción de este Estado, con independencia del lugar de comisión de los hechos, siempre que el hecho sea constitutivo de delito en el lugar de comisión de los hechos. Disponible en: http://www.legislation.gov.uk/ukpga/2001/17. Última consulta en agosto de 2016. ${ }^{42}$ Vid. REDRESS, Op. cit., pp. 262-263.

${ }^{43}$ En aplicación de la Sección 134 del "Criminal Justice Act de 1988” que confiere jurisdicción universal sobre los crímenes de tortura y se aplica a cualquier persona de cualquier nacionalidad, actuando en el Reino Unido o en cualquier otro lugar; y en aplicación del "Taking ok hostages Act 1982", que en su sección 1 confiere jurisdicción universal sobre el crimen de toma de rehenes, y cualquier acto contrario a la Convención internacional contra la toma de rehenes, de 1982. Disponibles en inglés en: http://www.legislation.gov.uk/ukpga/1982/28/section/1?timeline=true\&view=plain http://www.legislation.gov.uk/ukpga/1988/33/section/134. Última consulta en agosto de 2016.

${ }^{44}$ Finalmente fue declarado incapacitado para ser juzgado, aunque la fundamentación de su acusación se encuentra en el "War crimes Act 1991", que concede jurisdicción sobre delitos constitutivos de asesinato,
} 
Del mismo modo que desarrollábamos las regulaciones anteriores, debemos apuntar que existen normativas duales, que a primera vista pueden dar la impresión de reconocer la entidad y sobre todo la necesidad de la justicia universal, y que si se estudian en profundidad se muestran condicionadas por requisitos procesales que no son numerus clausus, sino que dejan margen de apreciación e interpretación a determinadas instituciones estatales. Este es el caso de la legislación alemana en la que se ha incluido la jurisdicción universal en términos absolutos, mediante la aprobación de un Código de Crímenes contra el Derecho Internacional ${ }^{45}$ con respecto a los crímenes en él tipificados, "incluso cuando el delito se haya cometido en el extranjero y no guarde relación con Alemania" ${ }^{" 46}$, y mediante la aplicación del Código Penal Ordinario ${ }^{47}$ de forma extraterritorial, y sin embargo, se regulan restricciones procesales importantes. Así, la fiscalía tiene lo que se denomina el "principio de oportunidad"48, que hemos visto ya en algunas de las legislaciones precedentes, que le proporciona la posibilidad de no perseguir determinados hechos punibles: si el responsable no se encuentra en el territorio nacional ni se espera su presencia, si la sospecha no recayera sobre un alemán, o si encontrándose en territorio alemán el sospechoso, se haya solicitado la entrega por un Tribunal Penal Internacional o la extradición por un Estado con título jurisdiccional preferente y esta entrega o extradición sea admisible y esté prevista ${ }^{49}$.

homicidio u homicidio culposo cometido en Alemania o en territorio ocupado alemán durante la segunda guerra mundial por cualquier persona, independientemente de su nacionalidad en el momento del crimen, que era, o que posteriormente se convirtió en ciudadano británico o residente en el Reino Unido. Disponible en: http://www.legislation.gov.uk/ukpga/1991/13. Última consulta en agosto de 2016.

${ }^{45}$ Voelkerstrafgesetzbuch, VStGB. La entrada en vigor de este Código se produjo el 30 de junio del año 2002, conteniendo, según su artículo 1, disposiciones penales para los crímenes más graves de trascendencia para la comunidad internacional en su conjunto, adecuando así el derecho penal alemán al Estatuto de Roma de la corte penal Internacional. Vid. WERLE, G. Y JESSBERGER, F., "La punibilidad de los crímenes internacionales en el derecho interno alemán. El Código Penal internacional alemán", Revista Penal, $\mathrm{n}^{\circ}$ 12, 2003, pp. 126-142.

${ }^{46}$ VStGB, Article 1, Part 1 - General provisions, Section 1 - Scope of application. Disponible en inglés en: https://www.mpicc.de/files/pdf1/vstgbleng2.pdf.

47 (Strafgesetzbuch, StGB) Section 6 and 7. El derecho penal alemán rige extraterritorialmente para los hechos tipificados en la sección 6 del StGB, esto es, "hechos cometidos en el exterior contra bienes jurídicos protegidos internacionalmente", y para el supuesto recogido en la Sección 7, párrafo 2, apartado 2 del StGB, esto es, "hechos que se hayan cometido en el exterior cuando el hecho está amenazado con pena en el lugar de los hechos o cuando el lugar de los hechos no está sujeto a potestad punitiva y cuando el autor para el momento del hecho fuera extranjero, y no fuera extraditado (...) bien porque no se ha presentado una petición de extradición o porque ha sido negada o porque la extradición no es factible". Disponible en inglés en: https://www.gesetze-im-internet.de/englisch_stgb/englisch_stgb.html\#p0051. Última consulta en agosto de 2016.

${ }^{48}$ Vid. RODRÍGUEZ YAGÜE, C., Op. cit., p. 51.

49 Strafprozeßordnung, StPO, Section 153.f. Disponible en inglés en: https://www.gesetze-iminternet.de/englisch_stpo/englisch_stpo.html. 
Entre los procesos llevados a cabo en Alemania, son de resaltar los casos de Tadic y Sokolovic. El primero de ellos fue acusado en 1995 de liderar crímenes atroces contra los musulmanes hallados en los campos de detención en Yugoslavia, y aunque el proceso no finalizó con una sentencia condenatoria sino con la entrega del acusado al Tribunal Penal Internacional para la antigua Yugoslavia, es destacable que el Estado alemán sostenía la aplicabilidad del derecho penal alemán con arreglo al StGB, fundamentándola en el principio de justicia universal. El proceso de Sokolovic finalizó en 1999 con una resolución condenatoria por haber sido cómplice en un Genocidio y su trascendencia radica en que aun cumpliéndose los requisitos procesales restrictivos que apuntábamos antes, la Corte Federal Suprema mostró su predisposición a no requerirlos, en especial para los hechos cometidos en el extranjero que deben ser perseguidos por venir esta obligación impuesta por un Tratado internacional ${ }^{50}$.

El de la dualidad es igualmente el caso legislación australiana, en la que se ha positivizado la persecución de ciertos crímenes internacionales ${ }^{51}$, estructurando un sistema de diferentes categorías jurisdiccionales. De esta forma, para la categoría D crímenes de genocidio, crímenes contra la humanidad, crímenes de guerra y delitos de tortura, etc., entre otros-, los órganos australianos pueden actuar con independencia de que el hecho ocurra o no en Australia o el presunto responsable o la víctima tengan nacionalidad o residencia australiana, mientras que, para la categoría B - delitos de esclavitud, por citar un ejemplo—, sólo se da la actuación de las autoridades australianas si existe un vínculo de nacionalidad o residencia ${ }^{52}$. Tratándose los crímenes de Derecho internacional contenidos en la categoría D, es necesario el consentimiento del Fiscal General antes de que se inicie cualquier investigación, siempre que se trate de

\footnotetext{
${ }^{50}$ Vid. MARTÍNEZ ALCAÑIZ, A., "El principio de Justicia universal y los crímenes de guerra", Tesis doctoral, UNED, España, 2014, pp. 512-515, publicada en 2015 por la Editorial Dykinson.

${ }^{51}$ Vid. "Australian Views on the Scope and Application of the Principle of Universal Jurisdiction". Consideraciones emitidas en respuesta a la Resolución 64/117. Disponible en: http://www.un.org/en/ga/sixth/65/ScopeAppUniJuri_StatesComments/Australia.pdf.

${ }^{52}$ La categoría D está compuesta por crímenes de genocidio, crímenes contra la humanidad, crímenes de guerra y delitos de tortura que están prohibidos por la Division 268 y la Division 274 of the Criminal Code Act 1995. La categoría B se refiere a los delitos de esclavitud y delitos relacionados prohibidos por la división 270 of the Criminal Code, con independencia de si el presunto responsable se encontraba en Australia en el momento de la comisión o en el extranjero. Disponible en: https://www.legislation.gov.au/Details/C2016C00753/Html/Volume_2\#_Toc455662401. Última consulta en agosto de 2016.
} 
crímenes cometidos en el exterior, siendo la decisión que contenga este consentimiento, definitiva e irrecurrible ${ }^{53}$.

Para finalizar este apartado, nos referiremos a la República Popular China. Se trata un Estado defensor de la soberanía estatal, que entiende que la jurisdicción universal carece de una definición internacional clara y consistente, y por lo tanto no la incorpora a su ordenamiento jurídico ${ }^{54}$. No obstante, entiende que si se identifica como aquella en la que no existe nexo alguno entre el crimen y el Estado que pretende enjuiciar el asunto, tal jurisdicción sólo existe en lo que se refiere a los actos de piratería y en determinados supuestos cuando viene amparada por su inclusión en un tratado internacional, en los que su aplicación no puede ser ignorada sin incumplir las obligaciones contraídas por el Estado en dichos acuerdos, al igual que sucedía en el Reino Unido, y en Francia. Como consecuencia de este restrictivo reconocimiento los tribunales Chinos, no han enjuiciado ningún caso fundamentando su competencia en el principio de justicia universal, conociendo únicamente de casos relacionados con la piratería, para los cuales se declaran competentes de conformidad con la Convención de las Naciones Unidas sobre el Derecho del Mar y el Convenio para la represión de actos ilícitos contra la seguridad de la navegación marítima, pues el artículo 9 del Código Penal chino prevé que "este Código será aplicable a los delitos estipulados en los Tratados internacionales concluidos o ratificados por la República Popular China o sobre los que esta República ejerza jurisdicción criminal en el marco de las obligaciones prescritas en ellos y asumidas por la República" ${ }^{, 55}$.

\section{De una jurisdicción universal absoluta a una limitada: los casos de Bélgica y}

\section{España}

Trataremos aquí legislaciones paradigmáticas, como la del Estado de Bélgica y la del Estado español, que han pasado de ser Estados implicados en la lucha contra la

\footnotetext{
${ }^{53}$ Sections 268.121, 268.122 and 274.3 of the Criminal Code.

${ }^{54} \mathrm{Vid}$. "Information from and observations by China on the scope and application of the principle of universal jurisdiction". Respuesta a la Resolución 64/117. Disponible en: http://www.un.org/en/ga/sixth/65/ScopeAppUniJuri_StatesComments/China_E.pdf.

${ }^{55}$ Vid. MUÑOZ CONDE, F. " "La parte general del Código Penal de la República Popular China”, Revista Penal, No 15, 2005, pp. 85-104; ROBLES CARRILLO, M., "El principio de jurisdicción universal: Estado actual y perspectivas de evolución", Revista Española de Derecho Internacional, Vol. LXVI, 2014, 2, pp. 102-103.
} 
impunidad, concienciados de lo imprescindible que es la justicia universal frente a los abusos de derechos humanos y las atrocidades, que en numerosas ocasiones se cometen por personas integradas y amparadas por órganos estatales, y que en ningún caso van a encontrar el castigo que merecen, ni sus víctimas encontrarán la justicia y la reparación que se les debe.

Bélgica fue un Estado pionero en la aplicación del principio de justicia universal y en la actualidad tiene una de las regulaciones más restrictivas. Desde la ley relativa a la represión de las violaciones graves del derecho internacional humanitario en el año $1993^{56}$, de transposición del sistema previsto en las Convenciones de Ginebra de 1949 y sus dos Protocolos de 1977, se confería competencia a los órganos jurisdiccionales belgas para determinados crímenes, sin requerir nexo alguno entre el crimen y el Estado, configurando un principio de justicia universal absoluto ${ }^{57}$. Esta regulación tan amplia dio lugar a numerosas denuncias y procesos lo que comportó duras presiones internacionales que exigían su modificación, y así ocurrió en el año 2003 al considerarse que la ley vigente era inadecuada ${ }^{58}$. El resultado fue una legislación subsidiaria, facultando al Fiscal Federal para desestimar una denuncia sin necesidad de que el juez de instrucción instruya esa denuncia. El margen de discrecionalidad en este caso es bastante extenso pues textualmente la ley establece esta facultad si "se destaca que, en el interés de una buena administración de la justicia y en respeto de las obligaciones internacionales de Bélgica, este asunto debiera ser llevado ante las jurisdicciones

\footnotetext{
${ }^{56}$ Originariamente denominada "Ley del 16 de junio de 1993 relativa a la represión de infracciones graves a la convenciones internacionales de Ginebra del 112 de agosto de 1949 y a los protocolos I y II del 8 de junio de 1977, adicionales a la esta convención", a través de la Ley de 1999 cambia a "Ley relativa a la represión de violaciones graves del derecho internacional humanitario". Disponible en español en: http://www.derechos.org/nizkor/belgique/doc/belesp10feb99.html. Última consulta en agosto de 2016.

${ }^{57}$ Vid. "Observations by Belgium on the scope and application of the principle of universal jurisdiction". Respuesta a la Resolución 64/117. Disponible en:

http://www.un.org/en/ga/sixth/65/ScopeAppUniJuri_StatesComments/Belgium E.pdf.

${ }^{58}$ Ejemplo de estas denuncias son la dirigida contra el Primer Ministro israelí Ariel Sharon, acusándolo de matanzas producidas en campos de refugiados palestinos, contra el líder palestino Yasser Arafat o el presidente chino Jiang Zemin acusándolo de los crímenes contra los seguidores de la corriente de Falun Gong. Vid. MARTínEZ ALCAÑíZ, A., Op. cit., pp. 517 520. Reforma introducida por la "Ley que modifica la Ley del 16 de junio de 1993 relativa a la represión de violaciones graves al derecho internacional humanitario y el articulo $144^{\circ}$ del Codigo de Justicia" de 23 de abril de 2003. Disponible en español en:

http://www.derechos.org/nizkor/belgique/doc/belesp23abr03.html. Última consulta en
} agosto de 2016. 
internacionales, o ante del lugar donde los hechos fueron cometidos, o ante la del Estado a que pertenece el autor o a la del lugar donde éste se pueda encontrar y siempre que esta sea competente, independiente, imparcial y equitativa" ${ }^{\text {"59 }}$. En una reforma posterior, se limita la actuación de los tribunales belgas a los casos en lo que el presunto autor sea nacional belga o sea residente de larga duración ${ }^{60}$.

Análoga dirección ha seguido la legislación y la práctica judicial española, que de una jurisdicción universal absoluta ${ }^{61}$, sin que se exigiera ningún vínculo o conexión con el Estado español, ni mayor requisito que el principio de non bis in $i^{d e m}{ }^{62}$, se ha convertido en una de las más restrictivas. Con el paso de los años, la regulación de este principio se modificó a fin de acoger nuevos delitos que en la comunidad internacional empezaban a inquietar y para los que se suscribían acuerdos internacionales: así, delitos relativos a la corrupción de menores, a la mutilación genital femenina y al tráfico ilegal o inmigración clandestina de personas ${ }^{63}$. Aun siendo una regulación en términos absolutos, no fue hasta el año 1996 cuando se presentaron ante los tribunales españoles las primeras denuncias, por el Caso de Pinochet, por los delitos de genocidio, terrorismo y tortura a ciudadanos que fueron asesinados durante la Dictadura Militar Chilena (1973 $-1990)^{64}$.

\footnotetext{
${ }^{59}$ Artículo 7 de la Ley del 16 de junio de 1993 reformado por el artículo 5 de la Ley de 23 de abril de 2003.

${ }^{60}$ Reforma introducida por la "Loi relative aux violations graves du droit international humanitaire", de 5 de agosto de 2003. REDRESS, Op. cit., pp. 85-92.

${ }^{61}$ La primera manifestación del principio de justicia universal en España se dio con el artículo 23.4. de la Ley Orgánica 6/1985, de 1 julio, del Poder Judicial, BOE núm. 157, de 2 de julio de 1985.

${ }^{62}$ Vid. PIGRAU SOLÉ, A., La Jurisdicción Universal y su aplicación en España: la persecución del genocidio, los crímenes de guerra y los crímenes contra la humanidad por los tribunales nacionales, Oficina de Promoción de la Paz y de los Derechos Humanos, Generalitat de Cataluña, Barcelona, 2009, p. 88.

${ }^{63}$ Estas incorporaciones se produjeron con: la disposición final única de Ley Orgánica 11/1999, de 30 de abril, de modificación del Título VIII del Libro II del Código Penal, aprobado por Ley Orgánica 10/1995, de 23 de noviembre, publicada en BOE núm. 104, de 1 de mayo de 1999; el artículo único de Ley Orgánica 3/2005, de 8 de julio de modificación de la Ley Orgánica 6/1985, de 1 de julio, del poder judicial, para perseguir extraterritorialmente la práctica de la mutilación genital femenina, publicada en BOE Núm. 163, de 9 de julio de 2005; y el artículo 1.1 de Ley Orgánica 13/2007, de 19 de noviembre, para la Persecución Extraterritorial de tráfico ilegal o inmigración clandestina de personas, publicada en BOE núm. 278, de 20 de noviembre de 2007.

${ }_{64}^{6}$ Vid. REMIRO BROTÓNS, A, El caso Pinochet: Los límites de la impunidad, Biblioteca Nueva, Madrid, 1999.
} 
El Caso Pinochet tuvo gran relevancia, aunque finalmente no haya sido posible su condena ${ }^{65}$, y compartimos la idea de GARZÓN, de que "la condena y el cumplimiento de la pena, no es el único criterio disponible para medir el éxito de la aplicación" del principio de justicia universal $^{66}$. La apertura de una investigación puede revitalizar el sistema judicial $^{67}$, y no sólo eso, sino que ofrece a las víctimas el reconocimiento de su derecho a la justicia, su derecho a ver reparado el daño que se les ha causado, y el derecho a que el responsable sea perseguido, derivado de la naturaleza de los crímenes internacionales y que no puede limitarse por haber ocurrido los hechos en un territorio $\mathrm{u}$ otro $^{68}$. Posteriormente siguieron procesos como el de Guatemala, iniciado en el año 1999, con los relevantes pronunciamientos del Tribunal Supremo, en la Sentencia $327 / 2003^{69}$, favorable a la exigencia de requisitos adicionales para legitimar la intervención de la jurisdicción española, argumentando que "no corresponde a ningún Estado en particular ocuparse unilateralmente de estabilizar el orden, recurriendo al Derecho Penal contra todos y en todo el mundo, sino que más bien hace falta un punto de conexión que legitime la extensión extraterritorial de su jurisdicción”, y del Tribunal Constitucional en la Sentencia 237/2005 ${ }^{70}$, totalmente contraria a la exigencia de dichos requisitos, no contemplados en la ley, pues constituyen una vulneración del derecho a la

\footnotetext{
${ }^{65}$ Vid. AA.VV., Crimen internacional y jurisdicción universal. (El Caso Pinochet), Tirant Lo Blanch, Valencia, 2000.

${ }^{66}$ GARZÓN, B., "La consolidación del principio de jurisdicción universal: los casos de Argentina y Chile en España", Tiempo de paz, $\mathrm{n}^{\circ} 112,2014$ pp. 39-45.

${ }^{67}$ Ídem.

${ }^{68}$ Audiencia Nacional (Sala de lo Penal, Sección 3a) Sentencia núm. 19/2005 de 19 de abril, Fundamento de derecho Primero, Apartado 3, Ref. Aranzadi JUR 2005\132318. "los grandes crímenes internacionales (...) Determinan una excepción al principio de territorialidad, a favor de la competencia uti universi de los tribunales internos, en determinados supuestos, constituyendo un título válido internacionalmente para ejercer la propia jurisdicción, sin que suponga un acto ultra vires o más allá de las competencias del Estado en concreto". Vid. GIMENO SENDRA, V. y DÍAZ MARTÍNEZ, M., "Los presupuestos procesales del órgano jurisdiccional (I)", Derecho Procesal Penal, $2^{\circ}$ ed., COLEX, Madrid, 2007, pp. 140-142.

${ }^{69}$ Tribunal Supremo (Sala de lo Penal) Sentencia núm. 327/2003 de 25 de febrero. Ref. Aranzadi RJ 2003/2147, que en su Fundamento de Derecho Octavo refleja la idea que la inspira "no le corresponde a ningún Estado en particular ocuparse unilateralmente de estabilizar el orden, recurriendo al Derecho Penal, contra todos y en todo el mundo, sino que más bien hace falta un punto de conexión de legitime la extensión extraterritorial de su jurisdicción".

${ }^{70}$ Tribunal Constitucional, Sentencia núm. 237/2005 de 26 de septiembre, Ref. Aranzadi RTC12005\237, que comienza su exposición con la importancia del acceso a la jurisdicción que constituye "la sustancia medular", el "contenido propio y primario" del derecho a la tutela judicial efectiva y que el control por parte del constitucional de las resoluciones de inadmisión o de no pronunciamiento han de verificarse de forma intensa dada la influencia del principio pro actione, de "obligada observancia por los Jueces y Tribunales que impide que determinadas interpretaciones y requisitos establecidos legalmente para acceder al proceso obstaculicen injustificadamente el derecho a que un órgano judicial conozca o resuelva en Derecho sobre la pretensión a él sometida".
} 
tutela judicial efectiva ${ }^{71}$. Ante los órganos jurisdiccionales españoles tambien se siguieron otros procesos como los de Falun Gong, cuya primera querella se interpuso en octubre del año 2003, y del Tíbet, iniciado 1998, que originaron una fuerte presión internacional por parte del Gobierno chino y demostraron, una vez más, que la aplicación del principio universal no puede ser pacífica. Aunque los Estados más influyentes reconocieron este título jurisdiccional, la aceptación no es la misma cuando sus ciudadanos, o miembros de su aparato estatal, son el objeto de la investigación ${ }^{72}$.

Las presiones diplomáticas provocaron las dos modificaciones más importantes en la regulación española ${ }^{73}$. En el año 2009 se añadieron por LO 1/2009, de 3 de noviembre, tres requisitos para la aplicación de la justicia universal, siguiendo los pasos restrictivos y limitadores que desde el año 2003 marcó el legislador belga. Dichos requisitos son la presencia de los presuntos responsables en España, que la víctima tenga nacionalidad española y la existencia de un vínculo de conexión relevante con España. Con esta ley se introducía además: el principio de subsidiariedad, pues se requería que no haya otro procedimiento iniciado en otro Estado o Tribunal Internacional que suponga una persecución o investigación efectiva de los hechos; y la posibilidad de sobreseimiento de un proceso penal en España, si aquel procedimiento es iniciado ${ }^{74}$.

\footnotetext{
${ }^{71}$ Vid. REMIRO BROTÓNS, A., "Crímenes internacionales, Jueces Estatales", Política Exterior, no 134, 2010, p. 4; CHINCHÓN ÁLVAREZ, J., 2009, Op. cit., pp. 7-9; PIGRAU SOLÉ, A., "Desvirtuando la jurisdicción en España: del caso Guatemala a la Ley orgánica 18/2003 de Cooperación con la Corte Penal Internacional" en VARGAS GOMÉZ-URRUTIA, M., SALINAS DE FRÍAS, A., (Coord.) Soberanía del Estado y derecho internacional: homenaje al profesor Juan Antonio Carrillo Salcedo, Universidad de Sevilla, 2005, Vol. 2, pp. 1059-1083.

${ }^{72}$ Vid. ESTEVE MOLTÓ, J., "La Ley Orgánica 1/2014 de reforma de la jurisdicción universal: entre el progresivo avance de la globalización comercial y de la deuda y la no injerencia en los asuntos internos de China", Anuario Español de Derecho Internacional, Vol. 30, 2014, pp. 151-153. En el caso de Pinochet, el Gobierno de Chile, amenazó con hacer boicots comerciales e interponer demandas ante órganos jurisdiccionales internacionales en contra de España. Igualmente el Gobierno de Guatemala rechazó toda posibilidad de colaboración con España para el esclarecimiento de los hechos y desde el Reino de Marruecos se puso de manifiesto la disconformidad con la instrucción del caso de los Genocidios del Sáhara, cuyo proceso comenzó ante los tribunales españoles en el año 2006. Desde China, se calificaban las actuaciones españolas como "una difamación total, una absoluta mentira" y en otros casos investigados, como el de los Vuelos Ilegales de la CÍA iniciado 2006, y Jose Couso de 2003, por parte de Estados Unidos tampoco se encontró gran apoyo para una eficaz aplicación del principio.

${ }_{73}^{73}$ Vid. SÁNCHEZ LEGIDO, A., Op. cit., pp. 6-7.

${ }^{74}$ Artículo 23.4 y 5 de la Ley Orgánica 1/2009, de 3 de noviembre, complementaria de la Ley de reforma de la legislación procesal para la implantación de una nueva Oficina Judicial, por la que se modifica la Ley Orgánica 6/1985, de 1 de julio de 1985, del Poder Judicial. BOE núm. 266, de 4 de noviembre de 2009.
} 
En el año 2014, dado que los casos abiertos no se habían podido archivar con la anterior redacción del precepto, a través de LO 1/2014, de 13 de marzo se volvió a modificar la jurisdicción universal $^{75}$. Lejos de solventar la situación instaurada desde 2009, se trata nuevamente de una reforma, limitadora de derechos, incapaz de garantizar la justicia para las víctimas, o de actuar como mecanismo de prevención, favoreciendo la impunidad de los responsables. En esta ocasión, se han regulado condiciones particulares para cada uno de los delitos previstos en el artículo 23.4 exigiéndose: en el apartado a), que el procedimiento se dirija contra un español o contra un ciudadano extranjero que resida habitualmente en España, o contra un extranjero que se encontrara en España y cuya extradición hubiera sido denegada por las autoridades españolas, en el apartado a) para los delitos de genocidio, lesa humanidad o contra las personas y bienes en caso de conflicto armado; y en los apartados b) y c): que el procedimiento se dirija contra un español o, la víctima tuviera nacionalidad española en el momento de comisión de los hechos y la persona a la que se impute la comisión del delito se encuentre en territorio español, para los delitos de tortura y contra la integridad moral y los delitos de desaparición forzada. El artículo 23.4 sigue en sus apartados d) a o) recogiendo requisitos similares para cada una de las categorías de delitos ahí previstas ${ }^{76}$. Concluye en su apartado o) estableciendo que será competente la jurisdicción española para conocer de: cualquier otro delito cuya persecución se imponga con carácter obligatorio por un Tratado vigente para España o por otros actos normativos de una

\footnotetext{
75 Ley orgánica 1/2014, de 13 de marzo, de modificación de la Ley Orgánica 6/1985, de 1 de julio del Poder Judicial, relativa a la justicia universal. BOE núm. 63, de 14 de marzo de 2014.

${ }^{76}$ Los delitos no recogidos en el texto, a los que se refiere el artículo 23.4 de la Ley Orgánica del Poder Judicial, en sus apartados d) a o) son: delitos de delitos de piratería, terrorismo, tráfico ilegal de drogas tóxicas, estupefacientes o sustancias psicotrópicas, trata de seres humanos, contra los derechos de los ciudadanos extranjeros y delitos contra la seguridad de la navegación marítima que se cometan en los espacios marinos; delitos contenidos en el Convenio para la represión del apoderamiento ilícito de aeronaves, hecho en La Haya el 16 de diciembre de 1970; los delitos contenidos en el Convenio para la represión de actos ilícitos contra la seguridad de la aviación civil, hecho en Montreal el 23 de septiembre de 1971, y en su Protocolo complementario hecho en Montreal el 24 de febrero de 1988; los delitos contenidos en el Convenio sobre la protección física de materiales nucleares hecho en Viena y Nueva York el 3 de marzo de 1980; tráfico ilegal de drogas tóxicas, estupefacientes o sustancias psicotrópicas; delitos de constitución, financiación o integración en grupo u organización criminal o delitos cometidos en el seno de los mismos; delitos contra la libertad e indemnidad sexual cometidos sobre víctimas menores de edad; delitos regulados en el Convenio del Consejo de Europa de 11 de mayo de 2011 sobre prevención y lucha contra la violencia contra las mujeres y la violencia doméstica; trata de seres humanos; delitos de corrupción entre particulares o en las transacciones económicas internacionales; y delitos regulados en el Convenio del Consejo de Europa de 28 de octubre de 2011, sobre falsificación de productos médicos y delitos que supongan una amenaza para la salud pública.
} 
Organización Internacional de la que España sea miembro, en los supuestos y condiciones que se determine en los mismos.

Las críticas a estas reformas fueron inmediatas ${ }^{77}$, y se definió la nueva regulación como "una arbitraria categorización de las víctimas, y una laberíntica regulación en numerosos apartados y regímenes que intencionadamente deja en la mayor indefensión a las víctimas de los crímenes más graves, generando espacios injustificados de impunidad para sus perpetradores", que además planteaba serias dudas acerca de su constitucionalidad $^{78}$. Como consecuencia de esta nueva normativa, los primeros casos en archivarse fueron los del Tíbet y Falun Gong, cumpliendo así con el objetivo directo de las reformas, suavizar las discusiones y acusaciones políticas surgidas en las persecuciones de estos dirigentes chinos ${ }^{79}$.

Aunque el panorama pudiera parecer, en este punto, un poco desalentador, sin embargo, no todo es negativo. Desde los órganos jurisdiccionales se han intentado buscar cauces bastantes para permitir el seguimiento de las causas abiertas. El primero en posicionarse en contra de la reforma fue el Juez titular del Caso Couso, considerando que la nueva ley resultaba contraria al Derecho Internacional, concretamente al IV Convenio de Ginebra, que obliga a los Estados parte a perseguir el delito con independencia de la nacionalidad de los autores y las víctimas y con independencia del lugar en el que se hallen, tratándose de una obligación clara que no se puede reducir a una facultad del Estado Parte, apuntando además que en Estados Unidos no hay ningún proceso abierto que pueda proteger los intereses de las víctimas y castigar a los responsables del

\footnotetext{
77 Vid. ORIHUELA CALATAYUD, E., La jurisdicción universal en España, Real Academia de Legislación y Jurisprudencia de Murcia, 2016; SEGURA SERRANO, A., "Hacia una nueva reforma restrictiva del principio de Jurisdicción Universal en España", Revista Española de Derecho Internacional, Vol. LXVI (2014), 1, pp. 321-324; y, "Vicisitudes de la Jurisdicción Universal tras la reforma de la Ley Orgánica del Poder Judicial de 2014", Revista Española de Derecho Internacional, Vol. LXVI (2014), 2, pp. 316-319; MARTÍNEZ GUERRA, A., "La reforma de la "molesta" jurisdicción universal y sus primeras consecuencias", Eunomía. Revista en Cultura de la Legalidad, no 7, septiembre 2014 - febrero 2015; SÁNCHEZ LEGIDO, A., Op. cit. pp. 29-40.

${ }^{78}$ Vid. ESTEVE MOLTÓ, J., Op. cit., p. 180. Este autor ha apuntado que la nueva reforma puede suponer una derogación de facto del artículo 125 en relación con el artículo 9.3 ambos de la Constitución Española, la supresión del principio de complementariedad de la Corte Penal Internacional, contraria al artículo 10.3 de la Constitución y una regulación discriminatoria según se trate de unas víctimas u otras, contraria al artículo 14 .

${ }^{79}$ Audiencia Nacional (Sala de lo Penal, Sección Pleno) Auto núm. 38/2014 de 2 de julio de 2014 Ref. Aranzadi ARP|2014\1213, confirmada por Tribunal Supremo (Sala de los Penal, Sección 1ª) Sentencia núm. 296/2015 de 6 de mayo. Ref. Aranzadi JUR।2015\137698.
} 
delito $^{80}$. El éxito fue momentáneo, pues una vez dictada la sentencia del Tribunal Supremo en los casos contra los militares chinos, el Juez se encontró en la obligación de decretar el archivo de la causa. En su sentencia el Alto Tribunal establece, y así lo indica el Juez en su propia resolución de archivo, "una doctrina para el futuro y con pretensiones de constituir doctrina definitiva, con el objetivo de dar seguridad en la aplicación uniforme de la norma interpretada", sin embargo, no sin antes reconocer que: "la decisión del legislador será discutible y podrá provocar debates en torno a tal impunidad (...) más no corresponde a los jueces suplir al legislador" ${ }^{\natural 1}$. El archivo de la causa fue definitivamente decretado por el Tribunal Supremo en octubre de 2016. Entiende el Tribunal que ni el Derecho internacional convencional ni el consuetudinario imponen un modelo de jurisdicción universal absoluto o "in absentia” y que por lo tanto, la Ley Orgánica 1/2014, “aun cuando ha acogido una modalidad muy restrictiva de jurisdicción universal que contrasta con la regulación anterior”, no es contraria a los Tratados ni a la práctica judicial internacional ${ }^{82}$.

En el mencionado Caso del Tíbet la decisión del archivo ante la Audiencia Nacional no fue unánime, apuntando el voto particular a una posible inconstitucionalidad de la norma por discriminatoria y por vulneración del derecho a la tutela judicial efectiva, además de resultar contraria a las obligaciones que el derecho internacional convencional impone al Estado español de investigar y perseguir crímenes de guerra. En el caso de Guatemala se continuó con la investigación de los delitos de terrorismo una

\footnotetext{
${ }^{80}$ Auto de 17 de marzo de 2014, Sumario 27/2007, Juzgado Central de Instrucción n ${ }^{\circ} 1$, Audiencia Nacional. http://www.ara.cat/politica/Auto-no-aplica-ref_ARAFIL20140317_0002.pdf. Este auto resultó ser muy crítico con la reforma pues argumenta el Juez que el Poder Judicial debe velar por los derechos de los ciudadanos y controlar la actuación de poderes públicos y ciñéndose al principio de legalidad y la obligación constitucional de someter a los jueces al imperio de la ley.

${ }^{81}$ Auto de 9 de Junio de 2015, Sumario 27/2007, Juzgado Central de Instrucción $\mathrm{n}^{\circ}$ 1, Audiencia Nacional. http://estaticos.elmundo.es/documentos/2015/06/09/conclusion_caso_couso.pdf. Se procede a concluir el sumario del Caso Couso con fundamento en la Sentencia del Tribunal Supremo, no sin antes reconocer que: "pese a que existen múltiples esfuerzos y recomendaciones a nivel mundial para perseguir y sancionar este tipo de delitos, el delito quedaría impune".

${ }_{82}$ Sentencia del Tribunal Supremo (Sala de lo Penal) No 797/2016 de 25 de octubre de 2016. Recurso de Casación $\mathrm{N}^{\circ} 37 / 2016$. En esta resolución se alude igualmente a la doctrina del tribunal constitucional en materia de jurisdicción universal diciendo que: "la doctrina constitucional referida al acogimiento en nuestro ordenamiento de un modelo de Jurisdicción Universal absoluto e incondicionado está en relación con la amplitud de la normativa legal establecida expresamente por la LOPJ en su versión inicial, pero no constituye el único modelo admisible constitucionalmente de Jurisdicción Universal", admitiendo así la posibilidad de restringir su ámbito de aplicación, "siempre que se respete el contenido esencial de jurisdicción extraterritorial fundada en la naturaleza y gravedad de determinados delitos que afectan a la Comunidad internacional".
} 
vez comprobada la existencia de víctimas españolas y se extendió el título jurisdiccional universal al resto de delitos, por considerarse delitos conexos, argumentando que el objeto del proceso penal son los hechos y no los delitos ${ }^{83}$. Recientemente, además, hemos sido testigos de la reapertura del proceso seguido contra los responsables de un presunto genocidio nazi, en los campos de concentración en Alemania, iniciado por primera vez en el año 2007, y que se había sobreseído por la entrada en vigor de la LO $1 / 2014^{84}$. El Tribunal Supremo en este auto de reapertura califica la nueva regulación como sustancialmente restrictiva de los derechos de los ciudadanos españoles victimas de graves delitos en el extranjero excluyendo de forma extrema su acceso a la jurisdicción para defenderse dentro del territorio español, habida cuenta de las pocas probabilidades de que alguno de los responsables resida habitualmente en el territorio español ${ }^{85}$.

\section{CONCLUSIONES}

En este trabajo se ha pretendido desglosar, sin pretensión de exhaustividad, la legislación vigente en materia de jurisdicción universal en España y en otros países, muchos de ellos de nuestro entorno, así como su práctica judicial. Se aprecia, en las normativas estatales, una clara tendencia a limitar los supuestos de aplicación extraterritorial de la ley penal, en especial en aquellos casos en los que la intervención de los órganos jurisdiccionales de un Estado concreto no viene justificada por la presencia de vínculos legitimadores. En lo que al principio de justicia universal se

\footnotetext{
${ }^{83}$ Auto de 20 de mayo de 2014, Sumario 331/99, Juzgado Central de Instrucción n ${ }^{\circ}$ 1, Audiencia Nacional.

http://ep00.epimg.net/descargables/2014/05/20/bd7d91049aa9e6a107de1dd23ee1bfd8.pdf?rel=mas. En este auto, a pesar de la reforma de la Ley Orgánica del Poder Judicial, que a primera vista supondría el archivo de la causa por falta de competencia, salvo para los hechos constitutivos de delito de terrorismo, el juez decide no modificar su investigación y "extender el título jurisdiccional universal al resto de delitos; porque de otra forma se rompería la denominada continencia de la causa"... "además, hay hechos que pueden suponer la comisión de uno o más delitos" por lo que la Audiencia Nacional extiende su competencia al conocimiento de los delitos conexos.

${ }^{84}$ Auto de 14 de abril de 2014, Sumario 56/2009, Juzgado Central de Instrucción $\mathrm{n}^{\mathrm{o}}$ 2, Audiencia Nacional.

http://www.ligaproderechoshumanos.org/documentos/20140710_sala penal_audiencia nacional.pdf. A través de este auto, aplicando de forma automática la disposición transitoria de la Ley Orgánica 1/2014, de 3 de marzo, se procede a dar por concluido el sumario del Caso por los genocidios nazis.

85 Tribunal Supremo (Sala de lo Penal, Sección $1^{\text {a }}$ ) Auto de 18 de abril de 2016. Ref. Aranzadi RJ/2016/1929 El presente auto en relación al auto de la Audiencia Nacional de 14 de abril de 2014, deja "sin efecto el auto de sobreseimiento y archivo, al objeto de que se proceda a complementar la investigación en orden a constatar el fallecimiento de los procesados referido por la parte querellante".
} 
refiere, es reconocido por la mayoría de los países como aquel que confiere jurisdicción a cualquier Estado sobre los denominados crímenes de Derecho Internacional, aunque no se trate del Estado del territorio donde se ha cometido, o del Estado de la nacionalidad de la víctima o del responsable y sin mediar interés nacional alguno, fundamentándose la competencia únicamente en la naturaleza de los bienes jurídicos protegidos. En teoría, la configuración legal del principio debería ser concordante a esta definición, sin embargo, en la práctica, para poder operar, siendo preceptiva su inclusión en los ordenamientos jurídicos internos de cada Estado, el problema surge cuando no se pueden controlar ni uniformizar los criterios legislativos. La consecuencia directa es la disparidad de legislaciones, y aun siendo tan diferentes coinciden en su esencia, esto es, en la limitación de la aplicabilidad del principio, exigiendo unos u otros requisitos, para investigar, acusar, y finalmente enjuiciar.

Podemos afirmar sin duda alguna que los sistemas normativos que hemos desarrollado previamente, son lesivos de derechos fundamentales, y lo alarmante es que las restricciones vienen provocadas por motivos políticos y económicos, y aun sin entrar a fondo en estas razones, es posible discernir que no son los pertinentes. Si nos situamos en el contexto de la protección de los derechos humanos lesionados por crímenes tan atroces, e identificamos el principio de justicia universal como un mecanismo eficaz para contrarrestarlos, a través de la restricción de la utilización de este instrumento, el resultado evidente es la ausencia de protección en estos sucesos. Es igualmente preocupante el ardid empleado para limitar las actuaciones de los órganos jurisdiccionales, el que denominábamos principio de oportunidad y que se atribuye a la figura de la Fiscalía en algunos de los Estados estudiados. Esta oportunidad se traduce en la discrecionalidad en la decisión de perseguir, pues no se encuentran tasados los requisitos que se han de cumplir para no acusar a los presuntos responsables, empleándose conceptos jurídicos indeterminados, tales como "en interés de una buena administración de justicia”. Esta ordenación no hace sino sumirnos en la inseguridad jurídica, brillando por su ausencia la transparencia indispensable que debe exigirse a las actuaciones de los poderes públicos.

La práctica judicial no mejora la imagen de conjunto, pues frente a algunos casos que son esperanzadores, en los que efectivamente se ha conseguido condenar a los 
responsables, aparecen incontables casos en los que se han enjuiciado hechos constitutivos de crímenes de Derecho Internacional, fundamentándose la competencia de los Estados en títulos atributivos de la jurisdicción diferentes al principio de justicia universal. La idea final es que los Estados se muestran temerosos a utilizar el concepto de justicia universal, en orden a no alterar sus relaciones comerciales y políticas con los Estados que, teniendo potestad para actuar, argumentando su competencia en principios de atribución preferentes, no actúan en modo alguno.

Es la eterna problemática en el contexto internacional de la no injerencia en los asuntos internos de un Estado, pero, ¿estaríamos realmente hablando de asuntos propios de un Estado, cuando la última ratio de la justicia universal es la protección de los derechos humanos? ¿Es admisible que, después de todo el progreso logrado con grandes esfuerzos en esta materia, se confiera a una persona, cuya objetividad e imparcialidad no se puede garantizar, la potestad de decidir actuar o no en favor de esa protección? La respuesta que ofrecemos a ambos interrogantes es rotundamente no, la protección de los derechos humanos no puede y no debe encasillarse en los límites de una frontera, y mucho menos dejar márgenes tan amplios de discrecionalidad. Limitando el principio de justicia universal, al transigir ante las presiones y amenazas de boicots comerciales, lo que verdaderamente se está haciendo es canjear los derechos de las víctimas y sus familiares, y en definitiva de la Humanidad en su conjunto, por beneficios económicos, $\mathrm{y}$ nos preguntamos si es éste todo el progreso que hemos alcanzado desde que se reconociera en el ámbito internacional la universalidad de tales derechos humanos.

El Tribunal Supremo español, en la sentencia del Caso Guatemala, apuntaba que un Estado no puede asumir la tarea de estabilizar el orden internacional a través de su Derecho Penal interno, y que por ello a través del consenso internacional se habían previsto otras soluciones. Entre ellas: la adopción de Tratados internacionales que prevén los mecanismos a emplear en caso de su incumplimiento, como el Convenio contra el genocidio que permite recurrir a los órganos competentes de las Naciones Unidas para que éstos adopten las medidas que juzguen apropiadas para la prevención y la represión de actos de genocidio; la creación de Tribunales Penales Internacionales ad hoc, como los creados para Ruanda o para la antigua Yugoslavia; y la creación de la Corte Penal Internacional de carácter permanente. Es cierto que, al hablar de justicia 
universal no se puede obviar la existencia de estos mecanismos, sin embargo, consideramos que no se han de contemplar como instrumentos excluyentes, sino complementarios. El alcance de los acuerdos y tribunales internacionales está limitado por la extensión del consentimiento de los Estados, y en aquellos supuestos donde el consentimiento no legitime la intervención, es necesario permitir un mecanismo subsidiario que pueda dar cobertura a los hechos delictivos que no quedan amparados por los anteriores. 